\title{
Coexpression of Microsomal-Type Prostaglandin E Synthase with Cyclooxygenase-2 in Brain Endothelial Cells of Rats during Endotoxin-Induced Fever
}

\author{
Kanato Yamagata, ${ }^{1}$ Kiyoshi Matsumura, ${ }^{2}$ Wataru Inoue,,2 Takuma Shiraki, ${ }^{2}$ Kyoko Suzuki, ${ }^{1}$ Shin Yasuda, ${ }^{1}$ \\ Hiroko Sugiura, ${ }^{1}$ Chunyu Cao, ${ }^{3}$ Yasuyoshi Watanabe, ${ }^{3}$ and Shigeo Kobayashi ${ }^{2}$ \\ ${ }^{1}$ Department of Neuropharmacology, Tokyo Metropolitan Institute for Neuroscience, Fuchu 183-8526, Japan, \\ 2Department of Intelligence Science and Technology, Graduate School of Informatics, Kyoto University, Sakyo-ku, Kyoto \\ 606-8501, Japan, and ${ }^{3}$ Department of Neuroscience, Osaka Bioscience Institute, Suita, Osaka 565-0874, Japan
}

Fever is triggered by an elevation of prostaglandin $E_{2}\left(P G E_{2}\right)$ in the brain. However, the mechanism of its elevation remains unanswered. We herein cloned the rat glutathione-dependent microsomal prostaglandin E synthase (mPGES), the terminal enzyme for $\mathrm{PGE}_{2}$ biosynthesis, and examined its induction in the rat brain after intraperitoneal injection of pyrogen lipopolysaccharide (LPS). In Northern blot analysis, mPGES mRNA was weakly expressed in the brain under the normal conditions but was markedly induced between 2 and $4 \mathrm{hr}$ after the LPS injection. In situ hybridization study revealed that LPS-induced mPGES mRNA signals were mainly associated with brain blood vessels, especially vein or venular-type ones, in the whole brain area. Immunohistochemical study demonstrated that mPGESlike immunoreactivity was expressed in the perinuclear region of brain endothelial cells, which were identified as von Willebrand factor-positive cells. Furthermore, in the perinuclear region of the endothelial cells, mPGES was colocalized with cyclooxygenase-2 (COX-2), which is the enzyme essential for the production of the mPGES substrate $\mathrm{PGH}_{2}$. Inhibition of cyclooxygenase-2 activity resulted in suppression of both $\mathrm{PGE}_{2}$ level in the CSF and fever (Cao et al., 1997), suggesting that the two enzymes were functionally linked and that this link is essential for fever. These results demonstrate that brain endothelial cells play an essential role in the $\mathrm{PGE}_{2}$ production during fever by expressing COX-2 and mPGES.

Key words: prostaglandin E synthase; cyclooxygenase-2; endothelial cell; fever; prostaglandin $E_{2}$; brain
Fever has been recognized as a common sign of various diseases, and its proper management is still an important issue in modern medicine. Fever is phylogenically old, at least found among lower vertebrates, and seems to have some protective values against pathogens (Kluger, 1991). Studies during the last three decades provided three essential findings about the mechanism of fever (Dinarello et al., 1988; Kluger, 1991; Rothwell, 1997; Dinarello, 1999). First, fever is an elevation in body temperature controlled by the CNS. Second, the CNS activity toward fever is triggered by an elevation of a lipid mediator, prostaglandin $\mathrm{E}_{2}\left(\mathrm{PGE}_{2}\right)$, in the brain. Third, the elevation of $\mathrm{PGE}_{2}$ in the brain is brought about by the actions of proinflammatory cytokines, including interleukin-1- $\alpha / \beta$ (IL-1- $\alpha / \beta)$, IL-6, tumor necrosis factor $\alpha$, and interferons, which are all produced by activated immune cells in the periphery and in some cases in the brain. There still remains a question, however, as to how brain $\mathrm{PGE}_{2}$ is elevated by the cytokines during fever because these cytokines with molecular

\footnotetext{
Received Sept. 25, 2000; revised Dec. 27, 2000; accepted Jan. 24, 2001.

This work was supported by grants from the program Grants-in-Aid for Scientific Research (C) of the Japan Society for the Promotion of Science (to K.Y. and K.M.) and by grants from the Ministry of Education, Science, Sports, and Culture of Japan, the Japan Epilepsy Research Foundation, the Pharmacopsychiatry Research Foundation (to K.Y.), the Special Coordination Funds for Promoting Science and Technology from the Science and Technology Agency, Japan, and the Naito Foundation (to K.M.)

K.Y. and K.M. contributed equally to this study.

Correspondence should be addressed to Dr. Kanato Yamagata, Department of Neuropharmacology, Tokyo Metropolitan Institute for Neuroscience, 2-6 Musashidai, Fuchu 183-8526, Japan. E-mail: kyamagat@tmin.ac.jp.

Copyright (c) 2001 Society for Neuroscience 0270-6474/01/212669-09\$15.00/0
}

weights over $15 \mathrm{kDa}$ unlikely penetrate the blood-brain barrier to act on brain cells directly.

This question may be answered by histochemical localization of either $\mathrm{PGE}_{2}$ itself or $\mathrm{PGE}_{2}$-synthesizing enzymes in the brain during fever. $\mathrm{PGE}_{2}$ is biosynthesized through the following three enzymatic steps (Smith et al., 1991): first, phospholipase A2 (PLA2) acts on the membrane phospholipids to cleave arachidonic acid; second, cyclooxygenase (COX) converts arachidonic acid to $\mathrm{PGH}_{2}$; and finally, $\mathrm{PGE}$ synthase (PGES) converts $\mathrm{PGH}_{2}$ to $\mathrm{PGE}_{2}$. Among these enzymes, we previously demonstrated a strong induction of inducible-type of $\mathrm{COX}(\mathrm{COX}-2)$ in a subset, but not all, of the brain endothelial cells or perivascular cells in response to various fever-inducing agents (Cao et al., 1995, 1996, 1998; Breder and Saper, 1996; Elmquist et al., 1997; Lacroix and Rivest, 1998; Matsumura et al., 1998; Quan et al., 1998; Laflamme et al., 1999). Although this fact led us to hypothesize that brain endothelial cells are the sites of $\mathrm{PGE}_{2}$ production during fever, the final conclusion was hampered by the lack of evidence that PGES is also expressed in the brain endothelial cells. In this study, to test a hypothesis that PGES is induced in brain endothelial cells along with $\mathrm{COX}-2$, we cloned the rat homolog of human microsomal glutathione-dependent PGES (mPGES) (Jakobsson et al., 1999) from a rat testis cDNA library and examined histochemically the expressions of its mRNA and protein in the brain after systemic challenge with lipopolysaccharide (LPS), a potent exogenous pyrogen derived from the cell wall of Gramnegative bacteria. The results provided conclusive evidence that brain endothelial cells are the sites of $\mathrm{PGE}_{2}$ production in re- 
sponse to a peripheral pyrogenic challenge and, hence, play the central role in evoking fever.

\section{MATERIALS AND METHODS}

Materials. Male Wistar rats of 8 weeks of age were purchased from Shizuoka Laboratory Animal Cooperative (Shizuoka, Japan). They were housed four or five to a cage in the room at $26 \pm 2^{\circ} \mathrm{C}$ with a standard 12 hr light/dark cycle. Other materials and their sources are as follows: lipopolysaccharide of Escherichia coli 026:B6 (Sigma, St. Louis, MO); NS-398, a COX-2-specific inhibitor (a generous gift from Dr. S. Higuchi of Taisho Pharmaceutical, Tokyo, Japan); rabbit polyclonal antibody against human mPGES (Cayman Chemical, Ann Arbor, MI); goat polyclonal antibody against rat COX-2 (Santa Cruz Biotechnology, Santa Cruz, CA); sheep polyclonal antibody against rat von Willebrand factor (Affinity Biologicals, Ontario, Canada); TO-PRO3 (Molecular Probes, Eugene, OR); multiple-labeling grade secondary antibodies (Jackson ImmunoResearch, West Grove, PA); and $\mathrm{PGE}_{2}$ monoclonal enzyme immunoassay (EIA) kit (Cayman Chemical).

Cloning of rat $m P G E S c D N A$. To clone rat $m P G E S$ cDNA, we first amplified human $m P G E S$ cDNA from a human brain cDNA library (Clontech, Cambridge, UK) by using PCR with two mPGES-specific primers (5'-ATG CCT GCC CAC AGC CTG GTG ATG A-3' and 5'-TCA CAG GTG GCG GGC CGC TTC CC-3') (Jakobsson et al., 1999). The amplified DNA fragments were directly sequenced in both directions. Then we screened a rat testis cDNA library (Stratagene, La Jolla, CA) with human mPGES cDNA probe according to standard procedures (Sambrook et al., 1989). Briefly, $\sim 5 \times 10^{5}$ phages of the rat testis cDNA library were plated on the bacterial host XL1-Blue. Plaques were lifted onto Hybond-N membranes (Amersham Pharmacia Biotech, Uppsala, Sweden), and phage DNAs were denatured, neutralized, and cross-linked to the membranes. Human $m P G E S$ cDNA was labeled with $\left[\alpha^{-}{ }^{32} \mathrm{P}\right] \mathrm{dCTP}$ using the Random Primer DNA Labeling kit (TaKaRa, Tokyo, Japan). Membranes were hybridized with the radiolabeled human $m P G E S$ probe at $65^{\circ} \mathrm{C}$ for $18 \mathrm{hr}$ in a solution of $6 \times \mathrm{SSC}, 0.5 \% \mathrm{SDS}$, $5 \times$ Denhardt's reagent, and $0.1 \mathrm{mg} / \mathrm{ml}$ denatured salmon sperm DNA and finally washed in a solution of $2 \times \mathrm{SSC}$ and $0.5 \% \mathrm{SDS}$ at $50^{\circ} \mathrm{C}$ for 1 hr. Seven positive plaques were isolated, of which two containing the largest inserts were purified and cloned into pBluescript (pBS) using the Stratagene in vivo excision protocol. These two largest clones were sequenced in both directions.

Northern analysis. This procedure was performed as described previously (Linzer and Nathans, 1983) with $30 \mu \mathrm{g}$ of total RNA per lane. The probe used for Northern analysis was a $1.5 \mathrm{~kb}$ pair fragment of rat $m P G E S$ cDNA. The cDNA fragment was labeled by the random priming technique using $\left[\alpha^{-}{ }^{32} \mathrm{P}\right] \mathrm{dCTP}$.

In situ hybridization. Distribution of $m P G E S$ mRNA in the rat brain was examined at 2, 4, and $12 \mathrm{hr}$ after intraperitoneal injection of LPS (0.4 $\mathrm{mg} / \mathrm{kg}$ in $0.5 \mathrm{ml}$ of saline). At each time point, three rats were anesthetized with diethylether and perfused via the left ventricle with $50 \mathrm{ml}$ of ice-cold saline followed by $200 \mathrm{ml}$ of $4 \%$ paraformaldehyde solution in $0.1 \mathrm{M}$ phosphate buffer, $\mathrm{pH}$ 7.4. The brains were put in a solution containing $20 \%$ sucrose and $4 \%$ paraformaldehyde overnight and then frozen in dry-ice powder. The brain sections of $16 \mu \mathrm{m}$ thickness were made in a cryostat at $-25^{\circ} \mathrm{C}$ and mounted on 3-aminopropyltriethoxysilane-coated glass slides and stored at $-80^{\circ} \mathrm{C}$ until hybridized with riboprobes. ${ }^{35} \mathrm{~S}$-labeled rat $m P G E S$ antisense riboprobe was prepared from an appropriately restricted pBS plasmid containing nearly full-length rat $m P G E S$ cDNA. A sense strand ${ }^{35} \mathrm{~S}$-labeled rat $m P G E S$ probe of identical length was also made in a similar way and used for a negative-control experiment. The cryostat sections were fixed with $1 \%$

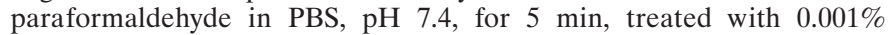
proteinase $\mathrm{K}$, acetylated, dehydrated in an ascending ethanol series, and air-dried. The sections were hybridized overnight $(16-18 \mathrm{hr})$ at $55^{\circ} \mathrm{C}$ in a humidified chamber with hybridization buffer $(50 \%$ formamide, $0.3 \mathrm{M}$ $\mathrm{NaCl}, 10 \mathrm{~mm}$ Tris-HCl, pH 8.0, 1 mm EDTA, $1 \times$ Denhardt's solution, $10 \%$ dextran sulfate, $10 \mathrm{~mm}$ dithiothreitol, and $0.5 \mathrm{mg} / \mathrm{ml}$ yeast RNA) containing $2 \times 10^{7} \mathrm{cpm} / \mathrm{ml}{ }^{35} \mathrm{~S}$-labeled riboprobe. After hybridization, the sections were washed, treated with RNase A, dehydrated in an ascending ethanol series, and air-dried. The sections were then exposed to Hyperfilm- $\beta$ max (Amersham Pharmacia Biotech) at $-20^{\circ} \mathrm{C}$ for 1 week. For microautoradiography, the sections were dipped in NTB2 emulsion (Eastman Kodak, Rochester, NY) diluted 1:1 with distilled water and exposed for 2 weeks at $4^{\circ} \mathrm{C}$. The films and sections on the glass slides were developed in Kodak D-19 at room temperature and fixed with Fuji Fix (Fujifilm, Tokyo, Japan). The sections were further lightly counterstained with $1 \%$ toluidine blue, dehydrated in an ascending ethanol series, and coverslipped.

Immunohistochemistry. For immunohistochemical detection of mPGES protein, rats were killed $5 \mathrm{hr}$ after intraperitoneal injection of LPS ( 0.1 or $0.4 \mathrm{mg} / \mathrm{kg}$ in $0.5 \mathrm{ml}$ of saline). This time point was selected because $m P G E S$ mRNA peaked at $4 \mathrm{hr}$ after the LPS treatment. Under anesthesia, the rats were perfused via the left ventricle with $50 \mathrm{ml}$ of ice-cold PBS (20 mM), pH 7.4. The brains were freshly frozen in dry-ice powder, cut at a thickness of $14 \mu \mathrm{m}$ in a cryostat, and thaw-mounted on glass slides. After having been air-dried at room temperature for $10 \mathrm{~min}$, the sections were treated with $0.02 \%$ sodium metaperiodate followed by $2 \%$ paraformaldehyde for $10 \mathrm{~min}$ each. The brain sections were treated with 10\% normal donkey serum (NDS) for $1 \mathrm{hr}$ and then incubated with anti-PGES (1:500 dilution) overnight at room temperature. After removal of the primary antibody, the sections were incubated with Cy3labled anti-rabbit IgG (1:500 dilution) for $90 \mathrm{~min}$. The anti-PGES antibody had been raised in rabbits against a peptide corresponding to amino acids 59-75 of human mPGES. With this antibody, Western blot analysis of sheep seminal vesicle and rat kidney was performed as described previously (Matsumura et al., 1998). The antibody (1:1000 dilution) properly recognized a $16 \mathrm{kDa}$ protein band corresponding to mPGES (see Fig. 5j). The specificity of the staining was confirmed with antibody preabsorbed with the antigen peptide $(1 \mu \mathrm{M})$ overnight at $4^{\circ} \mathrm{C}$. For visualization of the blood vessels, some of these sections were further incubated with sheep anti-von Willebrand factor $\operatorname{IgG}$ (1:3000 dilution) for $1 \mathrm{hr}$, followed by FITC-labeled anti-sheep IgG for $1 \mathrm{hr}$. The specificity of the double-immunostaining was confirmed by incubating the sections, which had been stained for mPGES, with sheep nonimmunized $\mathrm{IgG}$ instead of sheep anti-von Willebrand factor IgG.

In the case of double-immunostaining of mPGES and COX-2, rabbit anti-mPGES and goat-anti COX-2 were premixed so that their final dilutions became 1:500 and 1:2000, respectively. After overnight incubation of brain sections with the mixed antibodies at room temperature, one of the primary antibodies was visualized with a Cy3-labeled secondary antibody, and the other one with a biotin-labeled secondary antibody followed by FITC-avidin D. These secondary antibodies were of multiple-labeling grade (Jackson ImmunoResearch). Control experiments for the double-immunostaining of mPGES and COX-2 were done in two ways. First, the staining was done in the same way except that the primary antibody mixture was preabsorbed with either mPGES antigen peptide $(1 \mu \mathrm{g} / \mathrm{ml})$ or COX-2 antigen peptide $(1 \mu \mathrm{g} / \mathrm{ml})$. Second, the staining was done with a primary antibody mixture in which either mPGES or COX-2 was substituted with nonimmunized rabbit IgG or nonimmunized goat IgG, respectively. In both cases, inappropriate crossreactions were negligible. In some cases, the sections were further counter-stained for nuclear DNA with TO-PRO3. All antibodies were diluted with $10 \%$ NDS in $0.1 \mathrm{M}$ PBS, and all other chemicals were dissolved in 0.1 m PBS. Fluorescent images were captured by a threelaser confocal microscope (Radiance 2000; Bio-Rad, Hercules, CA).

Enzyme immunoassay for $P G E_{2}$ in the CSF. Rats were injected with a COX-2 inhibitor, NS398, (4 mg/kg, i.p.) or its vehicle [500 $\mu \mathrm{l}$ of $50 \%$ dimethylsulfoxide in saline] $1 \mathrm{hr}$ before the injection of LPS $(0.1 \mathrm{mg} / \mathrm{kg}$ in $0.5 \mathrm{ml}$ of saline) or saline. Five hours after the LPS or saline injection, the animals were anesthetized with pentobarbital, and their heads were fixed in a stereotaxic apparatus. CSF was sampled from the cisterna magna with a 27 gauge needle connected to a microsyringe $(0.25 \mathrm{ml})$ via PE20 tubing. The sampled CSF was immediately frozen in liquid nitrogen and stored at $-80^{\circ} \mathrm{C}$. On the day of assay for $\mathrm{PGE}_{2}$, the samples were thawed on ice, and $\mathrm{PGE}_{2}$ was extracted with organic solvent (ethylacetate). The extracted samples were assayed for PGE $_{2}$ with an EIA kit (Cayman Chemical) according to the manufacturer's instruction. Values were presented as the means \pm SEM. ANOVA followed by Scheffe's post hoc test was performed for the statistical analysis.

\section{RESULTS}

\section{Cloning of rat mPGES cDNA}

We have cloned a rat cDNA that was highly homologous to human $m P G E S$ by screening a rat testis library with human $m P G E S$ cDNA as a probe. This rat cDNA encoded a single open reading frame of 153 amino acids (Fig. 1A). Its nucleotide sequence was $84 \%$ identical to that of human $m P G E S$ cDNA (data not shown) (Jakobsson et al., 1999). Moreover, the amino acid sequence of the protein encoded by this cDNA was $79.7 \%$ iden- 


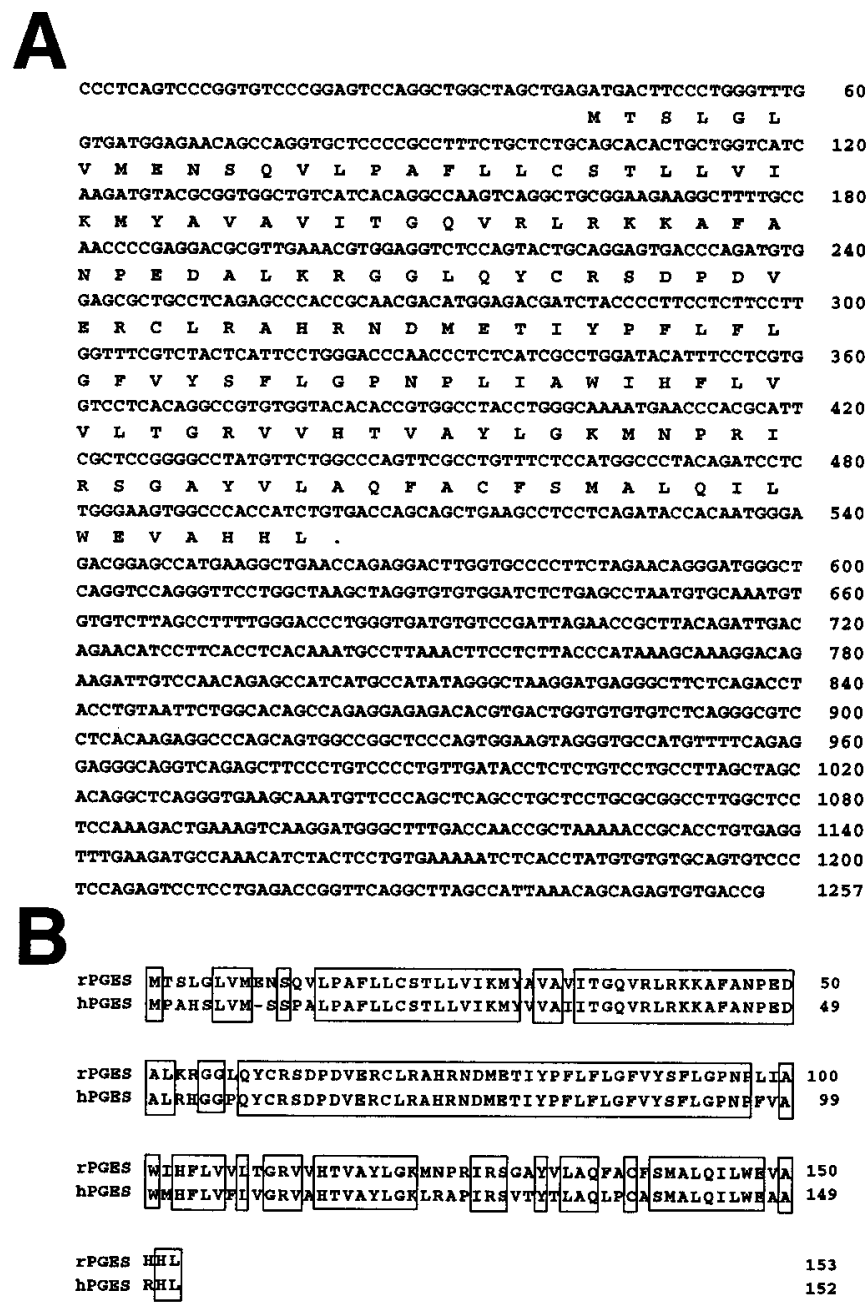

Figure 1. A, Nucleotide sequence of rat $m P G E S$ cDNA and its predicted amino acid sequence. Numbering for nucleotides, on the right, is from the start site of the largest cDNA. Two independent cDNAs were sequenced on opposite strands and yielded identical sequences. $B$, Comparison of the deduced amino acid sequences of rat (rPGES) and human (hPGES) PGES. Conserved amino acids between rat and human PGES are boxed.

tical to that of human mPGES (Fig. $1 B$ ). Its high homology to human $P G E S$ indicated that this novel gene encodes rat prostaglandin E synthase. The rat mPGES polypeptide contained one amino acid insertion near the $\mathrm{N}$ terminus (Glu at position 9).

\section{Tissue distribution and LPS induction of PGES mRNA}

The expression of rat mPGES mRNA was investigated in various tissues by Northern blot analysis using rat $m P G E S$ cDNA as a probe (Fig. 2A). Under the normal conditions, rat $m P G E S$ mRNA was $\sim 1.5 \mathrm{~kb}$ in size and was highly expressed in the kidney and testis. In the brain, the $m P G E S$ mRNA was weakly expressed in the cerebrum, cerebellum, and brainstem. These results are consistent with the expression pattern of human mPGES (Jakobsson et al., 1999), indicating that rat mPGES mRNA is expressed in the same kinds of tissues as the human.

To clarify whether $m P G E S$ gene expression is regulated in the brain by peripheral immunological stimuli, we assayed $m P G E S$ mRNA level in the rat brain by Northern analysis at different time points after the intraperitoneal injection of LPS (Fig. 2B). $m P G E S$ mRNA was hardly seen in the control brain in this case. This was because the exposure time was shorter than that in

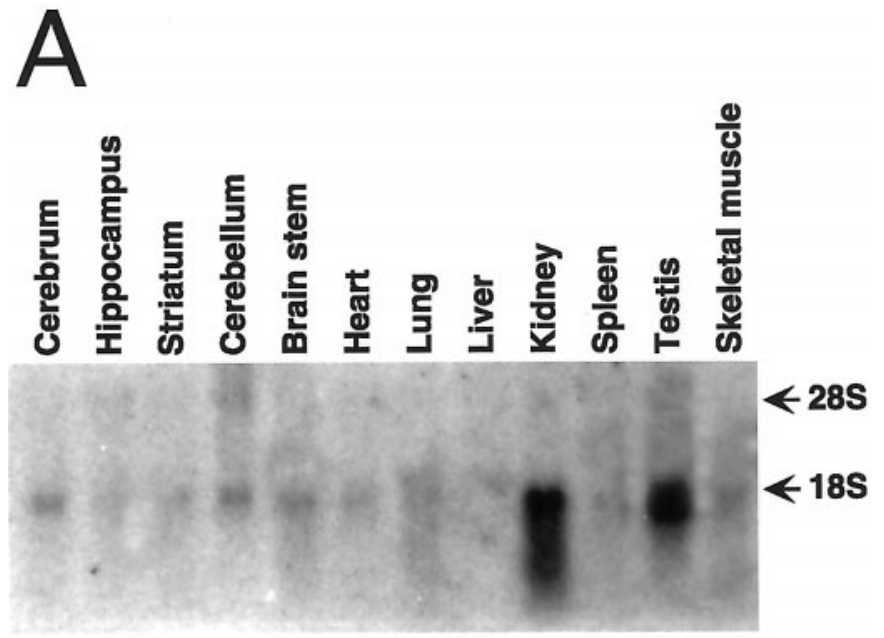

$B$

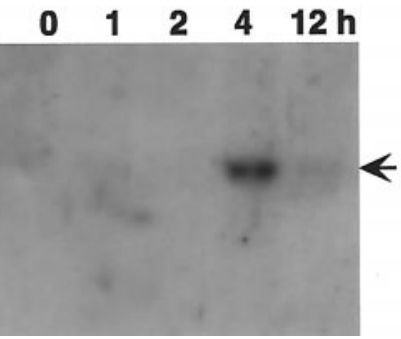

Figure 2. Expression and regulation of rat mPGES mRNA. Northern blot analysis of $30 \mu \mathrm{g}$ of total RNA per lane prepared from brain and peripheral tissues. $A$, Tissue distribution analysis shows that mPGES mRNA expression is enriched in the testis and kidney, with a low level of expression detected in the brain regions. $B$, Forebrain RNA at different time points $(0,1,2,4$, and $12 \mathrm{hr})$ after LPS injection $(0.4 \mathrm{mg} / \mathrm{kg}$, i.p.) reveal that LPS induced a transient increase in $m P G E S$ mRNA that peaked at $4 \mathrm{hr}$ and persisted through $8 \mathrm{hr}$.

Figure $2 A$. The $1.5 \mathrm{~kb} m P G E S$ mRNA was induced between 2 and $4 \mathrm{hr}$ and remained elevated for as long as $12 \mathrm{hr}$ after the injection.

\section{Brain localization of LPS-induced PGES mRNA}

Figure 3 shows macroautoradiographic images of the distribution of $m P G E S$ mRNA in the rat brain after the intraperitoneal injection of LPS. By $2 \mathrm{hr}$ after the injection, spot-like mRNA signals appeared in the brain parenchyma and on the brain surface (Fig. 3a,b). This type of signal was observed in the entire brain and spinal cord (data not shown). By $4 \mathrm{hr}$ after the injection, the mRNA signals had increased in both number and intensity (Fig. $3 c, d$ ). By $12 \mathrm{hr}$ after the injection, the mRNA signals had been reduced in intensity but still existed (Fig. $3 e, f$ ). No such spot-like signals were observed in the brains of untreated rat (data not shown) or saline-treated ones (Fig. $3 g$ ). Neither were such signals observed when the brain sections of LPS-treated rats were hybridized with the sense cRNA probe (Fig. $3 h$ ).

Figure $4 a-d$ shows light microscopic views of $m P G E S$ mRNA signals in the rostroventral part of the preoptic area, the area assumed to be the site of $\mathrm{PGE}_{2}$ action to evoke fever. In line with the macroscopic observation, the mRNA signals appeared by $2 \mathrm{hr}$ 

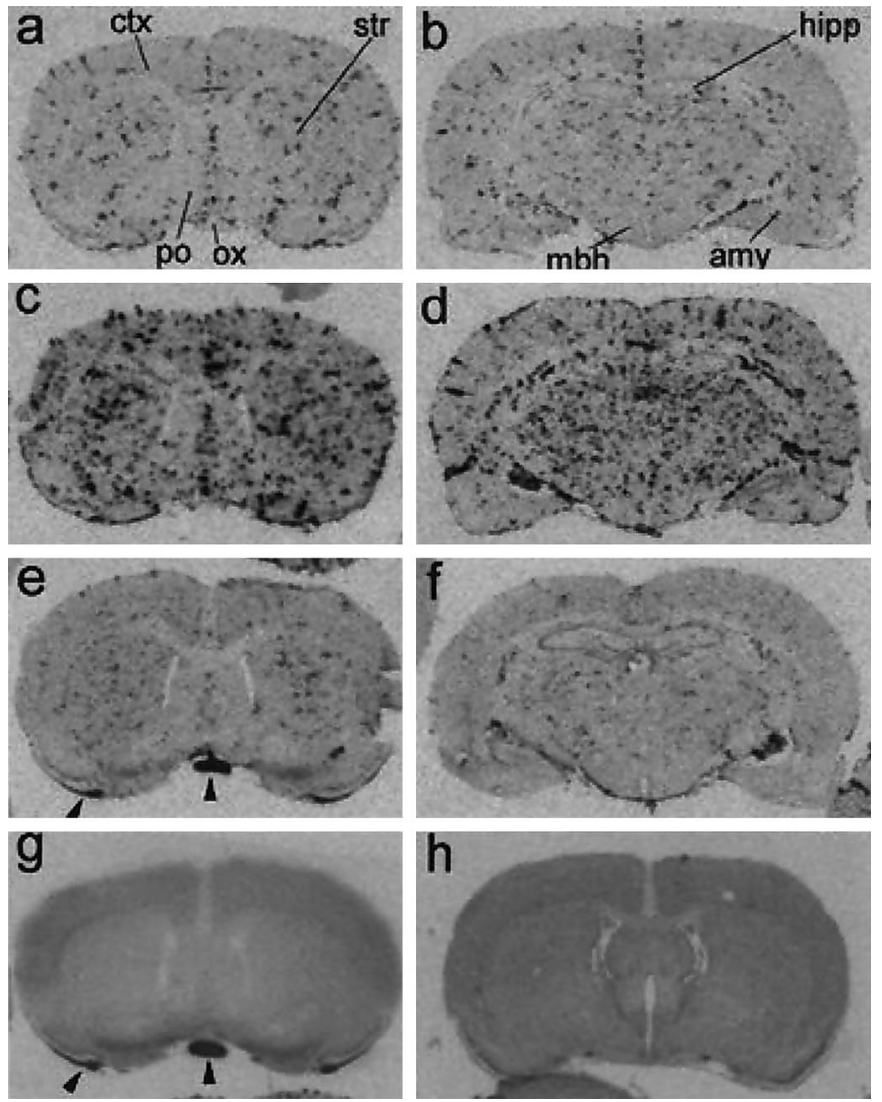

Figure 3. Macroautoradiographic images of $m P G E S$ mRNA signals in coronal sections of the rat brain. By $2 \mathrm{hr}$ after LPS injection $(a, b)$, the spot-like $m P G E S$ mRNA signals appeared in the brain parenchyma and subarachnoidal space. By $4 \mathrm{hr}$ after the injection $(c, d)$, the spot-like $m P G E S$ mRNA signals markedly increased in both number and intensity. At $12 \mathrm{hr}$ after LPS injection $(e, f)$, the mRNA signals were reduced in intensity but still existed. $m P G E S$ mRNA signals were not detectable in the brain section obtained $4 \mathrm{hr}$ after saline injection $(g)$. Hybridization with the sense cRNA probe did not show the spot-like signals in a brain section obtained $4 \mathrm{hr}$ after LPS injection $(h)$. The coronal planes in the left panels and $h$ contained cerebral cortex (ctx), striatum (str), preoptic area ( $p o$ ), and optic chiasma (ox). Those in $b, d$, and $f$ contained more caudal brain regions, including hippocampus (hipp), amygdala (amy), and mediobasal hypothalamus $(\mathrm{mbh})$. Arrowheads in $e$ and $g$ indicate nonspecific signals occasionally seen in the white matter at the edge of sections.

after the LPS injection (Fig. 4b), further increased by 4 hr (Fig. $4 c$ ), and became reduced by $12 \mathrm{hr}$ (Fig. 4d). No such signals were observed in the same brain region $4 \mathrm{hr}$ after the intraperitoneal injection of saline (Fig. 4a). In most cases, the LPS-induced mPGES mRNA signals were found in a cluster of cells associated with blood vessels (Fig. 4b,c, arrows). In a cross-section of a large blood vessel (Fig. 4e), the mRNA spots were aligned at a regular interval along the luminal side of the vessel wall. Figure $4 f$ shows another large blood vessel, which was axially sectioned, and, hence, its luminal surface was seen in the microscopic section. The luminal surface was tightly tiled with a number of $m P G E S$ mRNA-positive cells. Thus, it seems very likely that induction of mPGES mRNA occurred mainly in blood vessel endothelial cells in the brain. It should be noted that not all the blood vessels became positive for $m P G E S$ mRNA after the LPS challenge. Figure $4 g$ shows a blood vessel without the mRNA signals in a sample taken $4 \mathrm{hr}$ after the LPS injection. Figure $4 h$ shows a section of cerebral cortex taken $2 \mathrm{hr}$ after the LPS injection. There were three blood vessels seen in the section, but two of them were negative for the mRNA (indicated by arrowheads). Figure $4 i$ shows two large blood vessels in the subarachnoidal space, but only one of them was positive for the mRNA. In all cases described above, there was a common feature to the mPGES mRNA-negative blood vessels in that they possessed an apparent smooth muscle layer, which was identified by the sphincter muscle with the cellular nucleus being elongated in a direction perpendicular to the vessel axis (Fig. $4 g, h$ ) or by the thickened vessel wall (Fig. 4i). Thus, PGES mRNA seemed to be induced by LPS preferentially in the veins rather than in the arteries. It was hard to determine in the emulsion-coated autoradiography whether the capillaries also expressed mPGES mRNA. Even if they did so, however, the expression would not be so intense as that in the veins. In addition to its inducing effect on blood vessels, the LPS stimulus also induced $m P G E S$ mRNA expression in a certain type of cell in the brain parenchyma (Fig. 4j, arrows) and in the choroid plexus (Fig. $4 k$ ), although the signals were not so intense as those in the blood vessels. Such parenchymal cells with weak $m P G E S$ mRNA signals were seen in any brain regions after the LPS stimulus. The identity of these cells is not clear at present.

\section{LPS-induced PGES-like immunoreactivity in brain blood vessels}

Under the normal conditions, no mPGES-like immunoreactive (mPGES-IR) cells were found in the rat brain. After LPS challenge, mPGES-IR cells started to appear by $2 \mathrm{hr}$ and reached their highest level by $5 \mathrm{hr}$. The LPS-induced mPGES-IR structures were round or oval in shape (Fig. $5 a 1, b)$ and aligned along the vessel wall, as shown by double-immunostaining with von Willebrand factor, an endothelial marker (Fig. 5a2). Specificities of the staining of mPGES and von Willebrand factor were confirmed with preabsorbed anti-mPGES antibody (Fig. 5a3) and nonimmunized sheep IgG in substitution for anti-von Willebrand factor (Fig. 5a3, inset), respectively. Figure 5, $b$ and $c 1$, shows laser confocal microscopic images of mPGES-like immunoreactivity (red) and nuclear DNA (blue). mPGES-like immunoreactivity was most densely expressed in the perinuclear region. This perinuclear mPGES-IR structure was surrounded by von Willebrand factor (an endothelium-specific protein)-like immunoreactivity (Fig. 5c2, green). Thus, mPGES-like immunoreactivity was expressed in the perinuclear region of a subset of brain endothelial cells after the LPS challenge. Consistent with the in situ hybridization study, endothelial cells of arteries did not express mPGES-IR signals (Fig. 5d).

\section{Colocalization of PGES and COX-2}

It was shown previously that LPS induced COX-2 expression in the perinuclear region of brain endothelial cells (Matsumura et al., 1998). Therefore, coexpression of mPGES and COX-2 was examined in double-immunostained brain sections. As shown in Figure 5e1-e3, these two enzymes were coexpressed in a subset of endothelial cells. Among 109 endothelial cells positive for either mPGES or COX-2, the majority (96\%) were doublepositive for mPGES and COX-2, and only 1 and $3 \%$ were single-positive for mPGES and COX-2, respectively. Furthermore, their subcellular localizations almost overlapped in the perinuclear region (Fig. 5f1-f3). On the other hand, a subset of telencephalic neurons that constitutively expressed COX-2-like immunoreactivity did not show any mPGES-like immunoreactivity under both the control and LPS-challenged conditions, although endothelial cells nearby were positive for both (Fig. 5g1- 


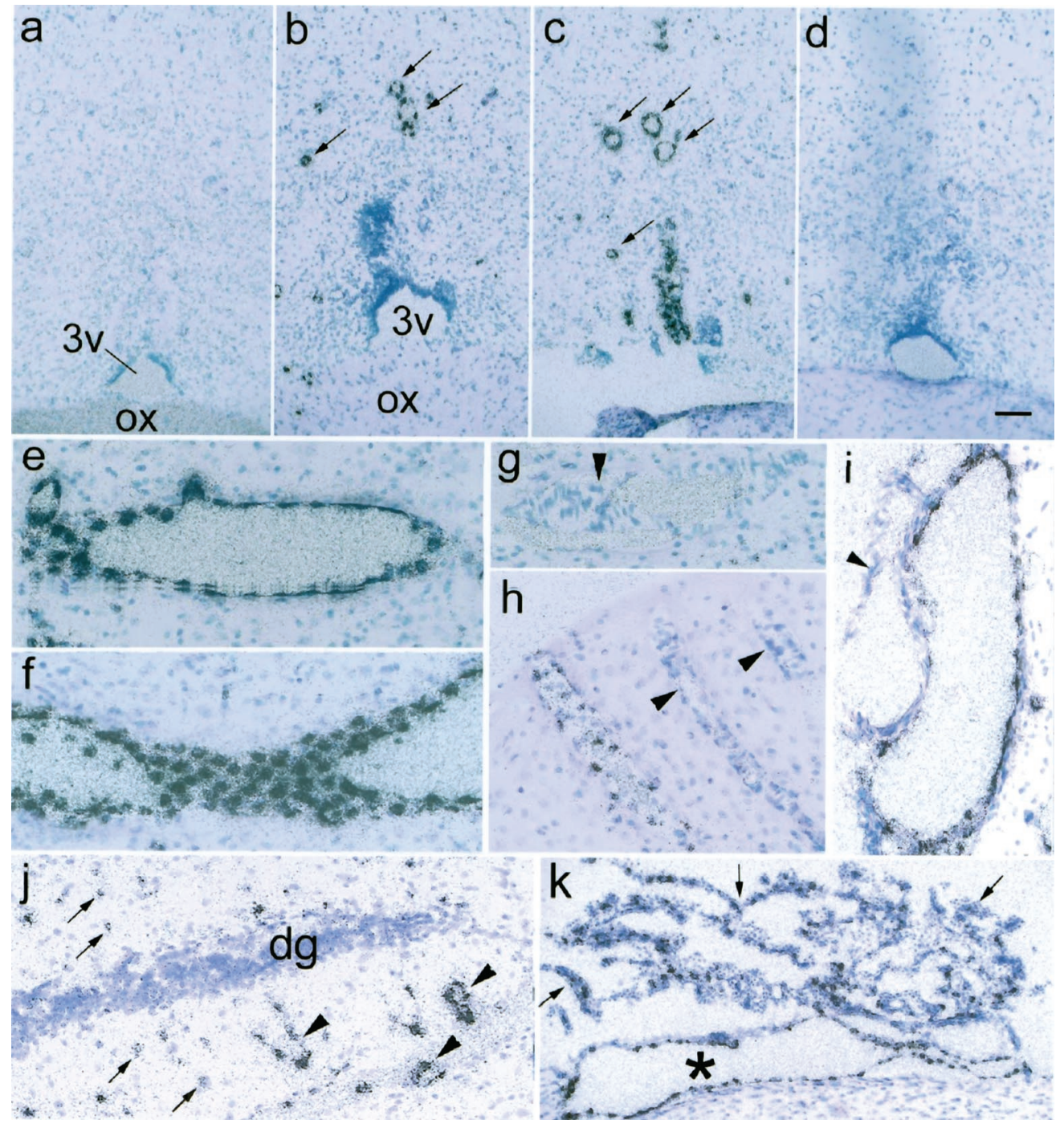

Figure 4. Light microscopic views of localization of $m P G E S$ mRNA. $a-d$, $m P G E S$ mRNA signals in the rostral part of the preoptic area $4 \mathrm{hr}$ after saline injection $(a)$, and $2(b), 4(c)$, and $12(d) \mathrm{hr}$ after the LPS injection. $3 v$, The third ventricle; $o x$, optic chiasma. Arrows in $b$ and $c$ indicate $m P G E S$ mRNA-positive cells associated with blood vessels. Most other mPGES mRNA-positive cells not denoted by arrows were also associated with blood vessels when examined under higher magnification. $e-k, m P G E S$ mRNA signals in brain parenchyma $(e-h, j)$, subarachnoidal space (i), and choroid plexus $(k) 4 \mathrm{hr}$ after the LPS injection, except for $h$, which was sampled at $2 \mathrm{hr}$ after the injection. Note that the artery-like blood vessels (arrowheads in $h$ and $i$ ) were devoid of the mRNA signals. $j$, Less intense $m P G E S$ mRNA signals (arrows) were occasionally seen in unidentified cells in the brain parenchyma along with intense mRNA signals associated with blood vessels (arrowheads). dg, Dentate gyrus of the hippocampus. $k$, mPGES mRNA signals were also expressed in the choroid plexus (arrows) and associated blood vessels (asterisk). Scale bar (in $d$ ): $a-d$, $k, 100 \mu \mathrm{m} ; e-j, 50 \mu \mathrm{m}$.

g3). Figure 5, $h 1$ and $h 2$, shows double-immunostaining for mPGES $(h 1$, red $)$ and COX-2 (h2, green) using the ordinary antibody mixture of anti-mPGES and anit-COX-2. In Figure 5, i1 and $i 2$, the adjacent section was incubated with the primary antibody mixture preabsorbed with COX-2 antigen peptide and visualized in the same way as in Figure $5 h$. Only staining for COX-2 was eliminated (Fig. 5i2), indicating that the anti-goat IgG antibody did not cross-react with rabbit anti-mPGES IgG. In a similar way, preabsorption of the primary antibody mixture with mPGES antigen peptide specifically eliminated mPGES staining but not COX-2 staining, indicating that the anti-rabbit IgG antibody did not cross-react with goat anti-COX-2 IgG (data not shown). The distinct staining pattern between neurons and endothelial cells in Figure 5, $g 1$ and $g 2$, also exclude the possibility that the anti-rabbit IgG antibody cross-reacted with goat antiCOX-2 IgG. Western blot analysis of rat kidney revealed that the antibody used for immunohistochemistry properly recognized rat mPGES (Fig. 5j).

\section{Functional link of PGES with COX-2 and its relevance to fever}

Coexpression of COX-2 and mPGES in the perinuclear region of brain endothelial cells led us to examine whether the two enzymes are functionally linked. The $\mathrm{PGE}_{2}$ level in the CSF was elevated $5 \mathrm{hr}$ after the LPS challenge (Fig. 6). This increase was completely suppressed when the rats had been pretreated with a COX-2-specific inhibitor, NS-398. This result indicates that mPGES is supplied with its substrate, $\mathrm{PGH}_{2}$, primarily through COX-2 after LPS challenge. Thus, mPGES and COX-2 are functionally linked under such a pathological condition. It is highly likely that this link takes place in brain endothelial cells, because they are the only cell group expressing both enzymes in the brain after the LPS challenge. The pretreatment with NS-398 also suppressed febrile response to LPS as reported previously (Cao et al., 1997). These results strongly suggest that brain endothelial cells are the primary source of the $\mathrm{PGE}_{2}$ that is essential for the fever response.

\section{DISCUSSION}

It is well established that $\mathrm{PGE}_{2}$ in the brain triggers a variety of CNS-mediated pathological responses associated with infectious or inflammatory diseases (Milton, 1982; Dinarello et al., 1988; Blalock, 1989). These responses, generally called "acute-phase response," include fever, hyperalgesia, and the activation of the hypothalamo-pituitary-adrenal axis (Kent et al., 1992). It was not fully clarified, however, where and how $\mathrm{PGE}_{2}$ is biosynthe- 
Figure 5. Immunostaining of mPGES, von Willebrand factor, and COX-2 in the rat brain $5 \mathrm{hr}$ after LPS injection. In all panels, red and blue indicate mPGES-like immunoreactivity and nuclear DNA staining, respectively. a1, mPGES staining is seen along the vessel wall. a2, mPGES staining is overlaid with von Willebrand factor staining (green) in the same brain section as in a1. a3, Incubation with preabsorbed anti-mPGES eliminated the staining in the same blood vessel seen in the adjacent section. a3, Inset, Control experiment for the double-immunostaining of mPGES and von Willebrand factor. Incubation of mPGES-stained section with nonimmunized sheep IgG instead of anti-von Willebrand factor resulted in virtually no staining of endothelial cytosol. $b$, mPGES-positive cells are seen along an axially cut blood vessel. $c 1$, Magnified view of mPGES-positive cells with nuclear DNA staining. $c 2$, von Willebrand factor staining ( green) is overlaid on mPGES and nuclear staining in $c 1 . d$, mPGES is negative in a large artery (asterisk) but is positive in small blood vessels nearby. mPGES staining $(e 1, f 1, g 1)$ is overlaid with COX-2 immunostaining $(e 2, f 2, g 2)$ and further with nuclear staining $(e 3, f 3, g 3)$. f1-f3, Perinuclear colocalization of mPGES and COX-2 is confirmed in enlarged views. $g 1-$ g3, mPGES and COX-2 are colocalized only in endothelial cells but not in cortical neurons (arrow), in which only COX-2 is expressed. $h 1, h 2, i 1, i 2$, Double-immunostaining of mPGES $(h 1, i 1)$ and COX-2 $(h 2, i 2)$ was performed using either the ordinary antibody mixture $(h 1, h 2)$ or the mixture preabsorbed with COX-2 antigen peptide $(i 1, i 2)$. Note that only COX-2 staining was eliminated after preabsorption with COX-2 antigen peptide. $j$, Western blot analysis of rat kidney revealed that the antibody used for immunohistochemistry properly recognized rat mPGES. Scale bars: $a 1-a 3,50 \mu \mathrm{m} ; b, 20 \mu \mathrm{m} ; c 1, c 2,5$ $\mu \mathrm{m} ; d, e 1-e 3, g 1-g 3, h 1, h 2, i 1, i 2,10 \mu \mathrm{m}$; and $f 1-f 3,2 \mu \mathrm{m}$.
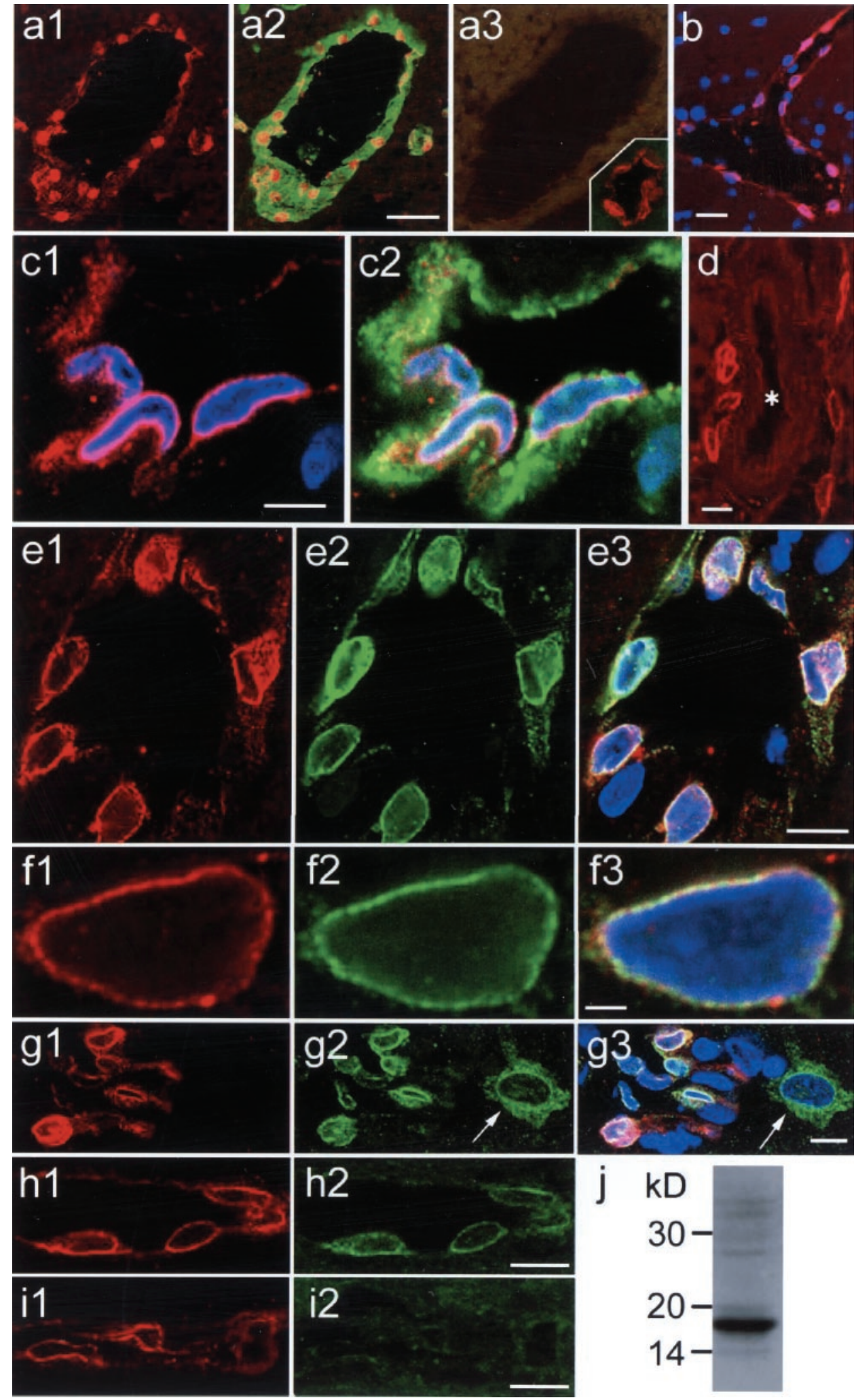

sized in the brain under such pathological conditions. This information would be of importance when fever and other symptoms should be controlled to avoid their adverse effects. To answer the question, we have been studying the brain expressions of enzymes responsible for $\mathrm{PGE}_{2}$ synthesis in animal models of infection. As discussed below, the present study strongly indicates that fever is evoked by $\mathrm{PGE}_{2}$ that is biosynthesized in the brain endothelial cells through COX-2 and mPGES enzymatic actions.

COX-2 was identified in 1991 as an inducible isoform of COX (Kujubu et al., 1991; Xie et al., 1991). It catalyzes the reaction from arachidonic acid to $\mathrm{PGH}_{2}$, a common substrate for several types of PG synthase, including PGES. A large number of studies 


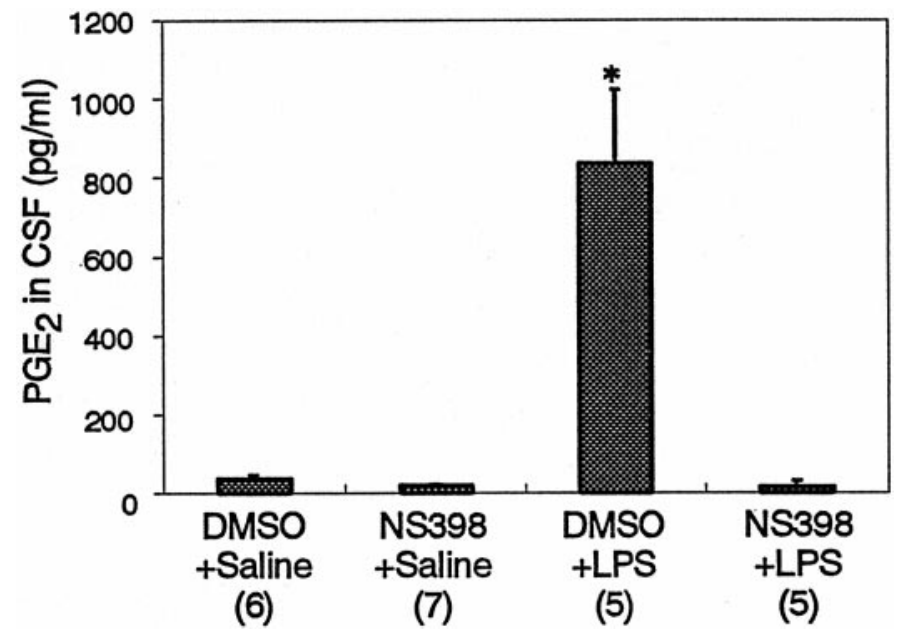

Figure 6. $\mathrm{PGE}_{2}$ level in the CSF $5 \mathrm{hr}$ LPS injection and effect of a COX-2-specific inhibitor. Numbers in the parentheses indicate the number of animals examined. ${ }^{*} p<0.0001$

during the last decade demonstrated that COX-2 is inducible by cytokines, viral infection, and mitogens, and plays pivotal roles in the development of inflammatory symptoms, cancer, and, possibly neurodegenerative diseases (Goppelt-Struebe, 1995; Herschman, 1996). We and others demonstrated that various pyrogenic stimuli induced COX-2 expression in brain blood vessels (Cao et al., 1995, 1996, 1998; Breder and Saper, 1996; Elmquist et al., 1997; Lacroix and Rivest, 1998; Matsumura et al., 1998; Quan et al., 1998; Laflamme et al., 1999), although there was controversy as to the type of cells that expressed COX-2, either endothelial cells (Matsumura et al., 1998) or perivascular microglia (Elmquist et al., 1997). Fevers evoked by various inflammatory agents were all suppressed by a COX-2-specific inhibitor (Futaki et al., 1993; Cao et al., 1997, 1999) or by $C O X-2$ gene disruption (Li et al., 1999) and were always associated with a concomitant expression of COX-2 in brain endothelial cells (Cao et al., 1997, 1999). These findings led us to hypothesize that brain endothelial cells are the sites of $\mathrm{PGE}_{2}$ production during fever, but at that moment, evidence was still lacking for the presence of PGES in the same endothelial cells expressing COX-2.

PGES activity, which catalyzes the conversion of $\mathrm{PGH}_{2}$ to $\mathrm{PGE}_{2}$, has long been recognized in various tissues. Partial purification of PGES activity indicated that there existed multiple isoforms of PGES (Urade et al., 1995; Watanabe et al., 1997, 1999), although they were not molecularly identified until recently. In 1999, Jakobsson et al. for the first time identified a human microsomal protein (designated as mPGES) that possessed glutathione-dependent PGES activity (Jakobsson et al., 1999). It should be particularly noted that mPGES was inducible by IL-1 $\beta$, an inflammatory cytokine, in a human macrophage cell line, suggesting the involvement of mPGES in inflammation and in the acute-phase response (Jakobsson et al., 1999; Forsberg et al., 2000). The present study for the first time revealed histochemically that mPGES was minimally expressed in the brain under the normal conditions but was induced in the brain endothelial cells after intraperitoneal injection of LPS. Recently, another PGES was molecularly identified (Tanioka et al., 2000). It is a cytosolic PGES (cPGES), which requires glutathione for the enzymatic activity and is constitutively expressed in various tissues. Its cellular localization in the brain remains to be studied.
COX-2 and mPGES were coexpressed in brain endothelial cells in a temporally and spatially similar manner, suggesting that they were functionally linked. The occurrence of this link in endothelial cells was evidenced by the facts that the inhibition of COX-2 activity resulted in a suppression of the $\mathrm{PGE}_{2}$ level in the $\mathrm{CSF}$, and no other brain cells coexpressed both of these enzymes during fever. Preferential coupling of COX-2 and mPGES was demonstrated recently in an in vitro experiment under a bettercontrolled experimental condition, in which a cell line was transfected with $m P G E S$ gene with either the $C O X-1$ or $C O X-2$ gene (Murakami et al., 2000). In this experiment, the cells transfected with $m P G E S$ and $C O X-2$ produced $\mathrm{PGE}_{2}$ from much lower concentrations of arachidonic acid in the medium compared with those transfected with $m P G E S$ and $C O X-1$. On the other hand, the same research group demonstrated that cPGES is functionally linked with $\mathrm{COX}-1$ in a marked preference rather than to COX-2 (Tanioka et al., 2000). Thus, although cPGES is expressed in some brain cells, its contribution to COX-2-mediated responses, such as LPS-induced $\mathrm{PGE}_{2}$ production and fever, would seem to be small, if any. The above three lines of evidence, that (1) fever and $\mathrm{PGE}_{2}$ elevation in the CSF are both COX-2mediated responses, (2) COX-2 and mPGES are coexpressed only in the endothelial cells as far as the brain is concerned, and (3) COX-2 is preferentially coupled with mPGES rather than with cPGES, led us to finally conclude that brain endothelial cells are the major source of $\mathrm{PGE}_{2}$ during fever.

It is generally assumed that $\mathrm{PGI}_{2}$ rather than $\mathrm{PGE}_{2}$ is the major prostanoid in the vascular system, and $\mathrm{PGI}_{2}$ plays an essential role in the regulation of vascular tone by acting on the arterioles. Although this is certainly true under the normal conditions, brain endothelial cells seem to markedly enhance their ability to produce $\mathrm{PGE}_{2}$ under immunologically stimulated conditions. This is in line with previous reports that $\mathrm{PGE}_{2}$ was secreted from cultured brain endothelial cells in a higher amount than $\mathrm{PGI}_{2}$ in response to LPS or cytokine stimuli (de Vries et al., 1995) and that $\mathrm{PGE}_{2}$-like immunoreactivity was detected in vivo in brain microvasculature after systemic LPS or cytokine administration (Van Dam et al., 1993, 1996). Of interest, the present study showed that the endothelial response to LPS seems to occur mainly in veins or venules, which have little smooth muscle in their walls. Therefore, $\mathrm{PGE}_{2}$ produced in these vessels should have little impact on the vascular tone. Rather, $\mathrm{PGE}_{2}$ elaboration seems to be one of the early events in brain during immunological insults. The mechanism of vessel-type specific inductions of mPGES and COX-2 is unclear at present.

Figure 7 illustrates our current view on the signaling pathway to fever. Circulating LPS and/or inflammatory cytokines derived from LPS-stimulated blood cells do not enter the brain because of the tight junction between the endothelial cells. Rather, they activate the corresponding receptors on the luminal surface of the endothelial cells in the brain. Activation of these receptors leads to transcription and translation of $C O X-2$ and $m P G E S$ genes, as shown in the present study, and also to translocation of cytosolic PLA2 (cPLA2) to the nuclear envelope (Glover et al., 1995). Translocated cPLA2 cleaves nuclear membrane phospholipids to release arachidonic acid. Arachidonic acid is then converted to $\mathrm{PGH}_{2}$ by $\mathrm{COX}-2$ and finally to $\mathrm{PGE}_{2}$ by mPGES, because both enzymes are located near the nuclear membrane, as shown in the present study. $\mathrm{PGE}_{2}$ is then released into the brain and acts on the neurons possessing the EP3 subtype of $\mathrm{PGE}_{2}$ receptor (Ushikubi et al., 1998). This neuronal activation switches on the 


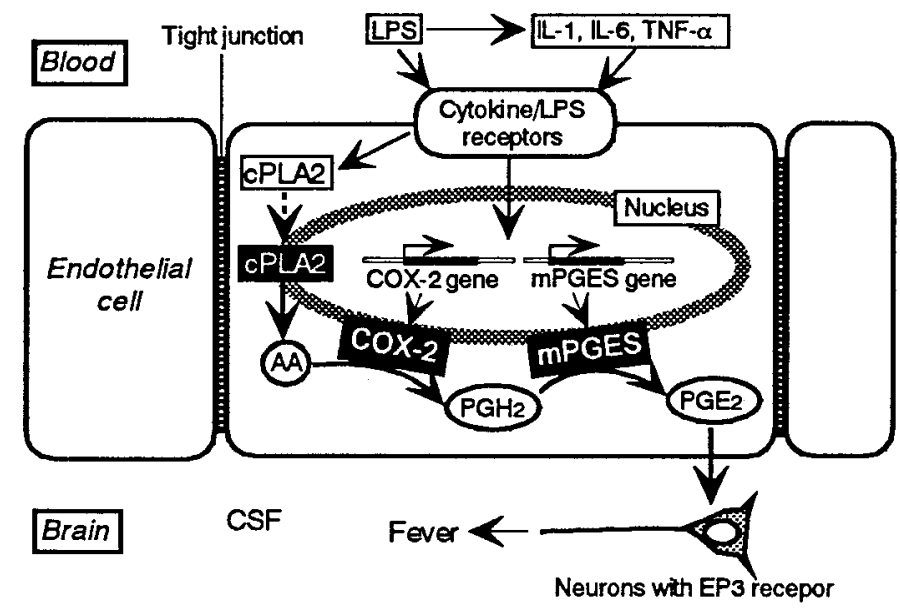

Figure 7. Our current hypothesis on the signaling cascade leading to fever in which brain endothelial cells play a pivotal role. See Discussion for the details. Dashed arrow indicates translocation of cPLA2. Other arrows indicate the flow of either molecules or signals

neuronal circuit to increase heat production and suppress heat loss, and as a consequence, the body temperature elevates.

There has been a long discussion as to how the immune system communicates with the CNS (Rothwell and Hopkins, 1995; Watkins et al., 1995; Blatteis and Sehic, 1997; Rothwell, 1997). The present study strongly indicates that, at least under the present experimental conditions, brain endothelial cells constitute one of the routes for immune-CNS communication, in which the endothelial cells transform the blood-borne immune signal into a $\mathrm{PGE}_{2}$ signal, which in turn acts on the CNS neurons to evoke fever and other acute-phase responses. Thus, brain endothelial cells are not merely a physical barrier between blood and brain but also act as a signal transducer between the immune system and the nervous system.

\section{REFERENCES}

Blalock JE (1989) A molecular basis for bidirectional communication between the immune and neuroendocrine systems. Physiol Rev 69:1-32.

Blatteis CM, Sehic E (1997) Fever: how may circulating pyrogens signal the brain? News Physiol Sci 12:1-9.

Breder CD, Saper CB (1996) Expression of inducible cyclooxygenase mRNA in the mouse brain after systemic administration of bacterial lipopolysaccharide. Brain Res 713:64-69.

Cao C, Matsumura K, Yamagata K, Watanabe Y (1995) Induction by lipopolysaccharide of cyclooxygenase-2 mRNA in rat brain; its possible role in the febrile response. Brain Res 697:187-196.

Cao C, Matsumura K, Yamagata K, Watanabe Y (1996) Endothelial cells of the rat brain vasculature express cyclooxygenase-2 mRNA in response to systemic interleukin-1 $\beta$ : a possible site of prostaglandin synthesis responsible for fever. Brain Res 733:263-272.

Cao C, Matsumura K, Yamagata K, Watanabe Y (1997) Involvement of cyclooxygenase-2 in LPS-induced fever and regulation of its mRNA in the rat brain by LPS. Am J Physiol 272:R1712-R1725.

Cao C, Matsumura K, Yamagata K, Watanabe Y (1998) Cyclooxygenase-2 is induced in brain blood vessels during fever evoked by peripheral or central administration of tumor necrosis factor. Mol Brain Res 56:45-56

Cao C, Matsumura K, Ozaki M, Watanabe Y (1999) Lipopolysaccharide injected into the cerebral ventricle evokes fever through induction of cyclooxygenase-2 in brain endothelial cells. J Neurosci 19:716-725.

de Vries HE, Hoogendoorn KH, van Dijk J, Zijlstra FJ, van Dam AM, Breimer DD, van Berkel TJC, de Boer AG, Kuiper J (1995) Eicosanoid production by rat cerebral endothelial cells: stimulation by lipopolysaccharide, interleukin-1 and interleukin-6. J Neuroimmunol 59:1-8.

Dinarello CA (1999) Cytokines as endogenous pyrogen. J Infect Dis [Suppl 2] 179:S294-S304.
Dinarello CA, Cannon JG, Wolf SM (1988) New concept on the pathogenesis of fever. Rev Infect Dis 10:168-190.

Elmquist JK, Breder CD, Sherin JE, Scammell TE, Hickey WF, Dewitt D, Saper CB (1997) Intravenous lipopolysaccharide induces cyclooxygenase 2-like immunoreactivity in rat brain perivascular microglia and meningeal macrophages. J Comp Neurol 381:119-129.

Forsberg L, Leeb L, Thoren S, Morgenstern R, Jakobsson P (2000) Human glutathione dependent prostaglandin E synthase: gene structure and regulation. FEBS Lett 471:78-82.

Futaki N, Yoshikawa K, Hamasaka Y, Arai I, Higuchi S, Iizuka H, Otomo S (1993) NS-389, a novel non-steroidal anti-inflammatory drug with potent analgesic and antipyretic effects, which causes minimal stomach lesions. Gen Pharmacol 24:105-110.

Glover S, Bayburt T, Jonas M, Chi E, Gelb MH (1995) Translocation of the $85-\mathrm{kDa}$ phospholipase A2 from cytosol to the nuclear envelope in rat basophilic leukemia cells stimulated with calcium ionophore or IgE/antigen. J Biol Chem 270:15359-15367.

Goppelt-Struebe M (1995) Regulation of prostaglandin endoperoxide synthase (cyclooxygenase) isozyme expression. Prostaglandins Leukot Essent Fatty Acids 52:213-222.

Herschman HR (1996) Prostaglandin synthase 2. Biochim Biophys Acta 1299:125-140.

Jakobsson PJ, Thoren S, Morgenstern R, Samuelsson B (1999) Identification of human prostaglandin E synthase: a microsomal, glutathionedependent, inducible enzyme, constituting a potential novel drug target. Proc Natl Acad Sci USA 96:7220-7225.

Kent S, Bluth RM, Kelley KW, Danzer R (1992) Sickness behavior as a new target for drug development. Trends Pharmacol Sci 13:24-28.

Kluger MJ (1991) Fever: role of pyrogens and cryogens. Physiol Rev 71:93-127.

Kujubu DA, Fletcher BS, Varnum BC, Lim RW, Herschman HR (1991) TIS10, a phorbol ester tumor promoter-inducible mRNA from Swiss 3T3 cells, encodes a novel prostaglandin synthase/cyclooxygenase homologue. J Biol Chem 266:12866-12872.

Lacroix S, Rivest S (1998) Effect of acute systemic inflammatory response and cytokines on the transcription of the genes encoding cyclooxygenase enzymes (COX-1 and COX-2) in the rat brain. J Neurochem $70: 452-466$.

Laflamme N, Lacroix S, Rivest S (1999) An essential role of interleukin-1beta in mediating NF-kappaB activity and COX-2 transcription in cells of the blood-brain barrier in response to a systemic and localized inflammation but not during endotoxemia. J Neurosci 19:10923-10930.

Li S, Wang Y, Matsumura K, Ballou LR, Morham SG, Blatteis CM (1999) The febrile response to lipopolysaccharide is blocked in cyclooxygenase-2 $(-/-)$, but not in cyclooxygenase-1 $(-/-)$ mice. Brain Res 825:86-94.

Linzer DI, Nathans D (1983) Growth-related changes in specific mRNAs of cultured mouse cells. Proc Natl Acad Sci USA $80: 4271-4275$

Matsumura K, Cao C, Ozaki M, Morii H, Nakadate K, Watanabe Y (1998) Brain endothelial cells express cyclooxygenase-2 during lipopolysaccharide-induced fever: light and electron microscopic immunocytochemical studies. J Neurosci 18:6279-6289.

Milton AS (1982) Prostaglandins in fever and the mode of action of antipyretic drugs. In: Pyretics and antipyretics (Milton AS, ed), pp 259-267. Berlin: Springer.

Murakami M, Naraba H, Tanioka T, Semmyo N, Nakatani Y, Kojima F, Ikeda T, Fueki M, Ueno A, Oh-Ishi S, Kudo I (2000) Regulation of prostaglandin $\mathrm{E}_{2}$ biosynthesis by inducible membrane- associated prostaglandin $\mathrm{E}_{2}$ synthase that acts in concert with cyclooxygenase-2. J Biol Chem 275:32783-32792.

Quan N, Whiteside M, Herkenham M (1998) Cyclooxygenase 2 mRNA expression in rat brain after peripheral injection of lipopolysaccharide. Brain Res 802:189-197.

Rothwell NJ (1997) Sixteenth gaddum memorial lecture, December 1996. Neuroimmune interactions: the role of cytokines. Br J Pharmacol 121:841-847.

Rothwell NJ, Hopkins SJ (1995) Cytokines and the nervous system. II. Actions and mechanisms of action. Trends Neurosci 18:130-136.

Sambrook J, Fritsch EF, Maniatis T (1989) Molecular cloning. New York: Cold Spring Harbor Laboratory.

Smith WL, Marnett LJ, DeWitt DL (1991) Prostaglandin and thromboxane biosythesis. Pharmacol Ther 49:153-179.

Tanioka T, Nakatani Y, Semmyo N, Murakami M, Kudo I (2000) Molecular identification of cytosolic prostaglandin $\mathrm{E}_{2}$ synthase that is functionally coupled with cyclooxygenase- 1 in immediate prostaglandin $\mathrm{E}_{2}$ biosynthesis. J Biol Chem 275:32775-32782.

Urade Y, Watanabe K, Hayaishi O (1995) Prostaglandin D, E, and F synthases. J Lipid Mediat Cell Signal 12:257-273.

Ushikubi F, Segi E, Sugimoto Y, Murata T, Matsuoka T, Kobayashi T, 
Hizaki H, Tuboi K, Katsuyama M, Ichikawa A, Tanaka T, Yoshida N, Narumiya S (1998) Impaired febrile response in mice lacking the prostaglandin E receptor subtype EP3. Nature 395:281-284.

Van Dam AM, Brouns M, Man-A-Hing W, Berkenbosch F (1993) Immunocytochemical detection of prostaglandin $\mathrm{E}_{2}$ in microvasculature and in neurons of rat brain after administration of bacterial endotoxin. Brain Res 613:331-336.

Van Dam AM, De Vries HE, Kuiper J, Zijlstra FJ, De Boer AG, Tilders FJ, Berkenbosch F (1996) Interleukin-1 receptors on rat brain endothelial cells: a role in neuroimmune interaction? FASEB J 10:351-356.

Watanabe K, Kurihara K, Tokunaga Y, Hayaishi O (1997) Two types of microsomal prostaglandin $\mathrm{E}$ synthase: glutathione-dependent and -independent prostaglandin E synthases. Biochem Biophys Res Commun 235:148-152.

Watanabe K, Kurihara K, Suzuki T (1999) Purification and characterization of membrane-bound prostaglandin $\mathrm{E}$ synthase from bovine heart. Biochim Biophys Acta 1439:406-414.

Watkins LR, Maier SF, Goehler LE (1995) Cytokine-to-brain communication: a review and analysis of alternative mechanisms. Life Sci 57:1011-1026.

Xie WL, Chipman JG, Robertson DL, Erikson RL, Simmons DL (1991) Expression of a mitogen-responsive gene encoding prostaglandin synthase is regulated by mRNA splicing. Proc Natl Acad Sci USA 88:26922696. 